\title{
Corrigendum: Patients Unmet Needs in Chronic Rhinosinusitis With Nasal Polyps Care: A Patient Advisory Board Statement of EUFOREA
}

\begin{abstract}
N. Claeys ${ }^{1}$, M. T. Teeling ${ }^{1}$, P. Legrand ${ }^{1}$, M. Poppe ${ }^{1}$, P. Verschueren ${ }^{1}$, L. De Prins ${ }^{2}$, L. Cools ${ }^{2}$, L. Cypers ${ }^{2 *}$, W. J. Fokkens ${ }^{3,4}$, C. Hopkins ${ }^{3,5}$ and P. W. Hellings ${ }^{3,4,6,7}$
\end{abstract}

${ }^{1}$ Patient Advisory Board of the European Forum for Research and Education in Allergy and Airway Diseases, Brussels, Belgium, ${ }^{2}$ Patient Liaison Officers of the European Forum for Research and Education in Allergy and Airway Diseases, Brussels, Belgium, ${ }^{3}$ The European Forum for Research and Education in Allergy and Airway Diseases Scientific Expert Team Members, Brussels, Belgium, ${ }^{4}$ Department of Otorhinolaryngology, Head \& Neck Surgery, Academic Medical Center (AMC), Amsterdam, Netherlands, ${ }^{5}$ Guy's and St Thomas' Hospital, London Bridge Hospital, London, United Kingdom, ${ }^{6}$ Department of Otorhinolaryngology, Head and Neck Surgery, Universitair Ziekenhuis Leuven, Leuven, Belgium, ${ }^{7}$ Department of Otorhinolaryngology, University of Ghent, Ghent, Belgium

\section{OPEN ACCESS}

Approved by:

Frontiers Editorial Office, Frontiers Media SA, Switzerland

*Correspondence: L. Cypers

lindsay.cypers@euforea.eu

Specialty section

This article was submitted to Rhinology,

a section of the journal

Frontiers in Allergy

Received: 04 October 2021 Accepted: 12 October 2021 Published: 29 October 2021

Citation

Claeys N, Teeling MT, Legrand $P$, Poppe M, Verschueren P, De Prins $L$,

Cools L, Cypers L, Fokkens WJ, Hopkins C and Hellings PW (2021) Corrigendum: Patients Unmet Needs in Chronic Rhinosinusitis With Nasa

Polyps Care: A Patient Advisory Board Statement of EUFOREA.

Front. Allergy 2:789425.

doi: 10.3389/falgy.2021.789425
Keywords: nasal polyps, oral corticosteroids, quality of life, unmet needs, chronic rhinosinusitis

\section{A Corrigendum on}

Patients Unmet Needs in Chronic Rhinosinusitis With Nasal Polyps Care: A Patient Advisory Board Statement of EUFOREA

by Claeys, N., Teeling, M. T., Legrand, P., Poppe, M., Verschueren, P., De Prins, L., Cools, L., Cypers, L., Fokkens, W. J., Hopkins, C., and Hellings, P. W. (2021). Front. Allergy 2:761388. doi: 10.3389/falgy.2021.761388

In the original published article, there was an error in the Funding statement. The incorrect statement read "Funding was provided via an unrestricted grant to EUFOREA by Sanofi Genzyme." The correct statement is "Funding was provided via an unrestricted grant to EUFOREA by Sanofi Genzyme and Regeneron."

The authors apologize for this error and state that this does not change the scientific conclusions of the article in any way. The original article has been updated.

Publisher's Note: All claims expressed in this article are solely those of the authors and do not necessarily represent those of their affiliated organizations, or those of the publisher, the editors and the reviewers. Any product that may be evaluated in this article, or claim that may be made by its manufacturer, is not guaranteed or endorsed by the publisher.

Copyright $\odot 2021$ Claeys, Teeling, Legrand, Poppe, Verschueren, De Prins, Cools, Cypers, Fokkens, Hopkins and Hellings. This is an open-access article distributed under the terms of the Creative Commons Attribution License (CC BY). The use, distribution or reproduction in other forums is permitted, provided the original author(s) and the copyright owner(s) are credited and that the original publication in this journal is cited, in accordance with accepted academic practice. No use, distribution or reproduction is permitted which does not comply with these terms. 